\title{
Prophylaxis of primary ventricular fibrillation with tocainide in acute myocardial infarction
}

\author{
R W F CAMPBELL, I HUTTON, R A ELTON, R M GOODFELLOW, E TAYLOR \\ From the University Department of Cardiology, Freeman Hospital, Newcastle upon Tyme; University Department of \\ Medical Cardiology, Royal Infirmary, Glasgow; Medical Computing and Statistics Unit, University of Edinburgh; \\ and Astra Clinical Research Unit, Edinburgh
}

SUMMARY Within six hours of suspected acute myocardial infarction, 791 patients entered a randomised double blind study of combined intravenous and oral tocainide for the prophylaxis of primary ventricular fibrillation. Acute myocardial infarction was confirmed in 559 patients, of whom 278 had received tocainide. The study was terminated on the basis of a sequential statistical analysis which showed that in these patients tocainide was unlikely to reduce the incidence of primary ventricular fibrillation by as much as $50 \%$, primary ventricular fibrillation having occurred in $4 \%$ of the tocainide and $2 \%$ of the placebo patients. Significantly fewer tocainide treated patients were withdrawn for other serious ventricular arrhythmias. Mortality ( $1 \%$ in the tocainide group and $2 \%$ in the placebo group) was low with no statistically significant differences between the active and placebo groups. Unwanted effects of treatment were infrequent and rarely troublesome both in patients with and without acute myocardial infarction.

These results suggest that in the dosage used in this study tocainide does not exert an antifibrillatory action in the early phase of acute myocardial infarction.

Lignocaine, ${ }^{12}$ procainamide, ${ }^{3}$ quinidine, ${ }^{4}$ mexiletine,$^{5}$ and tocainide ${ }^{6}$ when given prophylactically can reduce ventricular arrhythmias during acute myocardial infarction. Of these, however, only lignocaine ${ }^{1}$ has been shown satisfactorily to reduce the incidence of primary ventricular fibrillation-a result obtained using a high intravenous dose which was associated with frequent unwanted effects. The failure of the other drugs to achieve a reduction of ventricular fibrillation might have been because of drug inefficacy but often the numbers of patients investigated were inadequate to observe a positive effect.

Primary ventricular fibrillation, an early complication of acute myocardial infarction, decreases in incidence exponentially from the onset of symptoms. Effective prophylaxis of this arrhythmia requires rapid attainment of "therapeutic" plasma drug levels. Oral drug administration, while convenient, is unlikely to meet this demand as gastrointestinal absorption is delayed in patients who have sustained acute myocardial infarction, particularly if they have received narcotic analgesia. ${ }^{8}$ Erratic absorption and local injection site problems are common with intramuscular drug administration. A combination schedule of intravenous loading and subsequent oral maintenance administration could theoretically provide rapid achievement of stable plasma levels with relative simplicity.

Tocainide, a structural analogue of lignocaine with class I antiarrhythmic actions, ${ }^{9}$ has been shown to be as effective as lignocaine in suppressing ventricular arrhythmias during acute myocardial infarction ${ }^{10}$ but in contrast to lignocaine it has high oral bioavailability and a long half life. ${ }^{11}$ Its lignocaine-like electrophysiological properties and the availability of intravenous and oral formulations prompted this study of its value for the prophylaxis of primary ventricular fibrillation in the acute phase of myocardial infarction.

\section{Patients and methods}

Twenty-six coronary care units throughout the United Kingdom and Eire participated in the study.* Patients of either sex, aged 70 years or less with a history suggestive of acute myocardial infarction within the previous six hours, werf considered for entry.

* See next page. 
Patients were excluded from the trial on the following grounds:

(1) Significant left ventricular failure defined as a combination of tachycardia, third heart sound, and dyspnoea with one of the following: basal post-tussive crepitations, radiographic pulmonary oedema, or radiographic pulmonary venous congestion-or as defined by the attending physician.

(2) Arrhythmias requiring specific treatment including ventricular tachycardia, ventricular fibrillation, or other arrhythmias, at the discretion of the attending physician.

(3) Cardiogenic shock (systolic blood pressure less than $90 \mathrm{mmHg}$ plus vasoconstriction and poor peripheral perfusion).

(4) Prior administration of an antiarrhythmic drug (including beta adrenoceptor blocking drugs).

(5) Second or third degree heart block.

(6) Sinus bradycardia with a heart rate of less than 60 beats/minute.

(7) Known hepatic or renal disease.

The remaining patients comprised the study population and were allocated on a randomised double blind basis to receive either tocainide or an identical inert placebo. Informed consent was not consistently sought from patients included in this study as it was considered not always appropriate to discuss the concept of ventricular fibrillation prophylaxis at a time when rest, sedation, relief of pain, and reassurance are important.

Patients treated with tocainide received $500 \mathrm{mg}$ tocainide hydrochloride in $50 \mathrm{ml}$ of $0.9 \%$ saline intravenously over 30 minutes followed immediately by a $600 \mathrm{mg}$ oral loading dose. Placebo treated patients received an infusion containing $0.9 \%$ saline and an identical placebo tablet. The timing of subsequent oral maintenance therapy was dependent upon the patient's coronary care unit admission time to permit standardised twice daily drug administration at 0800 hours and 2000 hours. Oral treatment was continued for 48 hours after admission to the trial.
In the first 20 patients in each participating centre a venous blood sample was taken two hours after the. oral loading dose of study medication for estimation o plasma tocainide levels.

Electrocardiograms were monitored in the conveno tional manner. Drugs for the management of pain an $\overline{\bar{\delta}}$ cardiac failure were given as required but no routing use of antiarrhythmic drugs or beta adrenoreceptom blocking drugs was permitted. The diagnosis of acute myocardial infarction in the study population was confirmed by the presence of two or more of the for lowing: typical history; characteristic electrocardiog graphic abnormalities (new $Q$ waves and/or sequentia ST and T wave changes); and an increase in serum enzyme concentrations to at least twice the uppej limit of normal for that particular laboratory.

Patients were withdrawn from the study if:

(1) The diagnosis of acute myocardial infarctiog was not confirmed (as above).

(2) Cardiogenic shock or significant left ventricula failure (as previously defined) developed.

(3) Significant arrhythmias occurred requiring other specific antiarrhythmic therapy.

(4) Second or third degree heart block occurred.

(5) Unacceptable unwanted effects developed which might have been attributable to the stud medication.

Details of patients entered in the study we recorded on special record cards which were returnea periodically to the Astra Clinical Research Unit where they were checked for completeness, accuracy, and consistency.

A review committee independent both of diret involvement in the study and of the sponsoring comp pany was responsible both for monitoring the safe and endpoints of the trial according to the predefined statistical conditions and for the classification of modes of death.

The trial could be terminated if any of the following five situations occurred:

(1) A one sided sequential test showed a significan reduction in the incidence of ventricular fibre

«The study group consisted of the following: Investigators

J E I Pohl, J R Crampton (Leicester General Hospital); A Irvine, A Kenmure (Aberdeen Royal Infirmary); J L Francis (Staffordshire General Infirmary, Stafford); A R Tanser, B Schlect (St Martin's Hospital, Bath); W B Hanley (Southport General Infirmary); P Beck, A-Hunter (Llandough Hospital, Cardiff); J G Murtagh, K Moles (Belfast City Hospital); R H Baxter, D McLean (Law Hospital, Carluke); S O'Donohue, G Tobin (St Vincent's Hospital, Dublin); C Rodger (Monklands District General Hospital, Airdrie); J W B Turner (Pontefract General Infirmary); M H Husaini (Tameside General Hospital, Ashton-under-Lyne); P M S Gillam (Salisbury General Infirmary); J Stoker (St James's
University Hospital, Leeds); H S Mather (Southmead Ger̃ eral Hospital); M J Walsh, B MacMahon, M Bakshi (\$ James's Hospital, Dublin); A S Ramsey, A P Grant (Lagag Valley Hospital, Lisburn); J D Eddy, R Keal (Good Hope General Hospital, Sutton Coldfield); K M Mackenzie (Th West Suffolk Hospital, Bury St Edmunds); A V Simmons, A Mellor (Chapel Allerton Hospital, Leeds); P Hickling (Addenbrooke's Hospital, Cambridge); R H Lloyd-Mostyg (King's Mill Hospital, Sutton in Ashfield); M J Goldber (The Groby Road Hospital, Leicester); W D Alexander, $\mathbf{A}$ Milne (Queen Mary's Hospital, Sidcup); A Myers (Roy鱼 Infirmary, Blackburn); A M Hoare (Wycombe General Hos pital, High Wycombe). 
lation on tocainide treatment at the $5 \%$ level. This test had a $95 \%$ power against the alternative that the incidence of ventricular fibrillation on tocainide treatment was $50 \%$ of that on placebo treatment.

(2) The sequential test showed no significant reduction (that is the incidence of ventricular fibrillation on tocainide treatment was greater than $50 \%$ of that on placebo treatment).

(3) On periodic examination of the data the incidence of the combination of death, ventricular fibrillation, bradycardia, hypotension, left ventricular failure, asystole, second or third degree heart block was higher in the tocainide treated patients than in those receiving placebo (statistical significance required $p<0.05$ ).

(4) On periodic examination of the data the incidence of any one of the following: death, ventricular tachycardia, bradycardia, hypotension, left ventricular failure, asystole, second or third degree heart block was higher in the tocainide treated patients (statistical significance required $\mathrm{p}<0.01$ )

(5) None of the above reasons for study termination occurred within two years of recruitment of the first patient.

Statistical analysis of the final results was by $\chi^{2}$ tests with Yates's correction for comparison of proportions or $t$ tests for comparison of means. Linear logistic multiple regression was used for the analysis of tocainide efficacy within strata defined by site of acute myocardial infarction.

\section{Results}

\section{STUDY TERMINATION}

The study was terminated with a non-significant difference in the incidence of ventricular fibrillation on sequential analysis (situation 2) suggesting that tocainide was unlikely to reduce ventricular fibrillation by as much as $50 \%$ (Fig.). This conclusion was

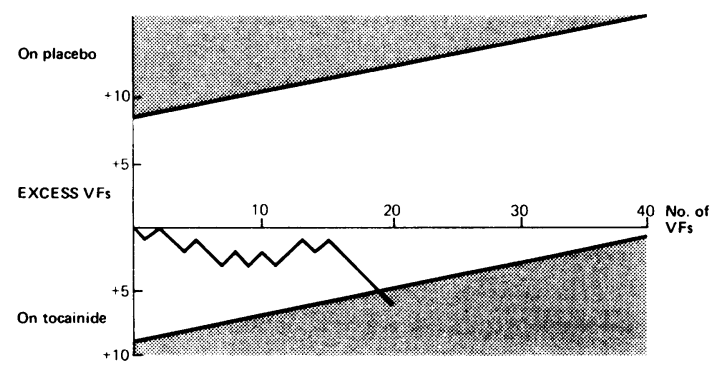

Fig. Sequential plot of incidence of ventricular fibrillation during course of the study. Shaded areas denote boundaries of predetermined study endpoints (see text). based upon analysis of all types of ventricular fibrillation but was confirmed on consideration of only primary ventricular fibrillation (in the absence of shock or cardiac failure) using fixed sample size procedures after the sequential test (confidence limits of relative risk $0.60,5.73$ ).

At the time of study termination, 791 patients had been entered. They will be considered in three subgroups.

\section{GROUP 1: PATIENTS WITH DEFINITE ACUTE MYOCARDIAL INFARCTION \\ Comparability of patients}

Clinical and electrocardiographic characteristics of the 278 tocainide and 281 placebo patients are shown in Table 1 . No statistically significant or important differences were present apart from a significant $(p<0.01)$ maldistribution of infarct site. A small excess of placebo patients entered the study within one hour of the onset of symptoms.

\section{Major endpoints (Table 2)}

Death: During drug administration, three tocainide and six placebo patients died (no significant difference).

During the study period (48 hours from inclusion in the study), six tocainide and eight placebo patients died. Three tocainide patients who were withdrawn (one for R-on-T ventricular extrasystoles, one for complete heart block, and one with heart failure) subsequently died within the study period (the first as a consequence of primary ventricular fibrillation, and the others from pump failure).

Two placebo patients who were withdrawn (one for $R$-on-T ventricular extrasystoles and one for ventricular tachycardia) later died (of cardiac rupture and pump failure, respectively) (Table 2).

Primary ventricular fibrillation: Primary ventricular fibrillation during drug administration occurred in nine tocainide and five placebo patients (not significant) and in 11 tocainide and six placebo patients during the 48 hour study period (not significant).

Withdrawals (excluding death and primary ventricular fibrillation): Thirty-six tocainide and 51 placebo patients were withdrawn during the course of the study (Tables 2 and 3). Eight tocainide and 28 placebo patients were withdrawn for ventricular arrhythmias judged to require therapy $(p<0.01)$. Within this group three tocainide and 11 placebo patients were withdrawn for ventricular tachycardia. Four patients were withdrawn for non-cardiac events (three tocainide patients: one for nausea/vomiting/sweating, one for vomiting, one for missed therapy, and one placebo patient for pre-existing depression).

Composite endpoint of death, primary ventricular 
Table 1 Patient characteristics in group 1

\begin{tabular}{|c|c|c|}
\hline & Tocainide & Placebo \\
\hline $\begin{array}{l}\text { No. of patients } \\
\text { Men/women } \\
\text { Age (y) } \\
\text { Heart rate (beats/min) } \\
\text { Systolic blood pressure (mmHg) } \\
\text { Diastolic blood pressure (mmHg) } \\
\text { Delay time (h) } \\
\text { Delay time }<1 \mathrm{~h} \\
\quad>1<3 \mathrm{~h} \\
\quad>3<6 \mathrm{~h} \\
\text { Delay time unknown } \\
\text { Previous acute myocardial infarction } \\
\text { Site of acute myocardial infarction-Anterior } \\
\\
\text { CK (IU/1) -Inferior }\end{array}$ & $\begin{array}{l}278 \\
222 / 56 \\
55 \pm 9 \star \\
78 \pm 14^{\star} \\
144 \pm 26^{\star} \\
93 \pm 40^{\star} \\
3 \cdot 4^{\star} \\
9 \\
135 \\
131 \\
3 \\
42 \\
108 \\
137 \\
33 \\
1457 \pm 1071^{\star}\end{array}$ & $\begin{array}{l}281 \\
235 / 46 \\
55 \pm 9 \star \\
79 \pm 13^{\star} \\
145 \pm 28^{\star} \\
90 \pm 18^{\star} \\
3 \cdot 3 \pm 1 \cdot 3^{\star} \\
13 \\
133 \\
132 \\
3 \\
48 \\
149 \\
109 \\
23 \\
1490 \pm 1171^{\star}\end{array}$ \\
\hline
\end{tabular}

$\star$ Mean \pm SD.

No statistically significant differences tocainide versus placebo except $(+) \mathrm{p}<0.01$.

Table 2 Major endpoints (death, primary ventricular fibrillation, or withdrawal)

\begin{tabular}{|c|c|c|c|c|c|c|}
\hline \multirow[t]{2}{*}{ Treatment category } & \multicolumn{2}{|l|}{ Group 1} & \multicolumn{2}{|l|}{ Group 2} & \multicolumn{2}{|l|}{ Group 3} \\
\hline & Tocainide & Placebo & Tocainide & Placebo & Tocainide & Placebo \\
\hline
\end{tabular}

Figures are events occurring during the $\mathbf{4 8}$ hour study period.

Figures in parentheses are events occurring during administration of trial drugs.

* One patient appears in both groups-totals account for this.

†Total number of patients who reached one or more of the above endpoints during the study period.

fibrillation, or withdrawal: Forty-eight tocainide and 61 placebo patients reached one or more of the above endpoints during the study period (Table 2).

GROUP 2: PATIENTS IN WHOM DIAGNOSIS OF DEFINITE ACUTE MYOCARDIAL INFARCTION WAS NOT CONFIRMED

This group consisted of 106 tocainide and 98 placebo

Table 3 Number of patients withdrawn from study in group 1 (excluding deaths and first primary ventricular fibrillation)

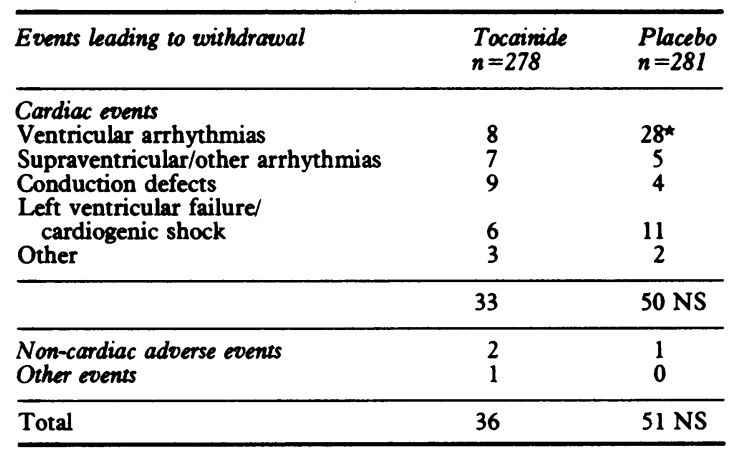

${ }^{\star} \mathrm{p}<0.01$. treated patients. One patient (tocainide) from this group died, aortic dissection being confirmed at necropsy. No episodes of primary ventricular fibrillation occurred. At a time before knowledge of the final diagnosis, 15 patients were withdrawn during the course of the study (seven tocainide patients: one for supraventricular tachycardia, two for bradycardia, one for hypotension, one for nausea, one selfdischarge, and one patient with hypotension and left ventricular failure who subsequently died after aortic dissection as described above, and eight placebo patients: two for bradycardia, one for left ventricular failure, one rash, one heroin addict, and three selfdischarge).

\section{GROUP 3: PATIENTS WHO DID NOT SATISFY PROTOCOL CONDITIONS AND PATIENTS \\ INADEQUATELY DOCUMENTED}

There were 22 patients entered who were subsequently found not to have satisfied the protocol inclusion criteria and a further six patients for whom inadequate information was recorded.

Two deaths occurred in this group, both being the result of pump failure in tocainide treated patients. One had been taking a beta adrenergic blocking drug before entry while the other had a heart rate of 54 
beats/minute on admission. One patient (placebo) developed primary ventricular fibrillation (he had been on a beta blocker). Fifteen patients were withdrawn from the study, of whom nine were withdrawn for cardiac events (six tocainide treated patients: three for ventricular arrhythmias, two for hypotension, one for left ventricular failure; and three placebo patients: two for ventricular arrhythmias including one with primary ventricular fibrillation, one for cardiogenic shock).

\section{OVERALL INCIDENCE OF UNWANTED EFFECTS}

The overall incidence of unwanted effects, both cardiac and non-cardiac, is presented in Table 4. There were no significant differences between the treatment groups with respect to either the total number or any specific adverse event.

\section{CHARACTERISTICS OF VENTRICULAR}

FIBRILLATION PATIENTS

Comparative clinical data for the 14 patients with primary ventricular fibrillation (in the absence of shock or cardiac failure) before withdrawal and the
545 patients without ventricular fibrillation is presented in Table 5. Ventricular fibrillation was significantly associated with inferior infarction, older age, and shorter onset of symptoms to admission times.

The comparative clinical data for patients in the tocainide and placebo groups are presented in Table 6 . There were no significant differences though there were more inferior infarcts in the tocainide group. In view of the discrepancy in site distribution of acute myocardial infarction between treatments, a stratified analysis of ventricular fibrillation incidence by site was also carried out. This resulted in a change in the confidence limits of relative risk from $0.60 / 5.73$ to $0.50 / 4.91$, the difference in incidence of ventricular fibrillation between the treatment groups remaining non-significant.

\section{TOCAINIDE PLASMA CONCENTRATIONS}

Tocainide plasma levels for 87 group 1 and 37 group 2 patients were obtained. The mean \pm SD plasma level in group 1 was $4.8 \pm 3.5 \mathrm{mg}$ base/l and $6.4 \pm 2.7$ in group $2(p<0.05)$. Thirty-two patients $(37 \%)$ in group

Table 4 Summary of incidence of adverse events (all patients)

\begin{tabular}{|c|c|c|c|c|c|c|c|}
\hline \multirow{2}{*}{$\begin{array}{l}\text { Treatment category } \\
\text { No. of patients }\end{array}$} & \multicolumn{2}{|l|}{ Group 1} & \multicolumn{2}{|l|}{ Group 2} & \multicolumn{3}{|l|}{ Group 3} \\
\hline & $\begin{array}{l}\text { Tocarinide } \\
278\end{array}$ & $\begin{array}{l}\text { Placebo } \\
281\end{array}$ & $\begin{array}{l}\text { Tocainide } \\
106\end{array}$ & $\begin{array}{l}\text { Placebo } \\
98\end{array}$ & Tocainide & 22 & Placebo \\
\hline $\begin{array}{l}\text { Cardiac events } \\
\text { Ventricular arrhythmias } \\
\text { Supraventricular arrhythmias } \\
\text { Conduction disturbances } \\
\text { Hypotension } \\
\text { Left ventricular failure } \\
\text { Other }\end{array}$ & $\begin{array}{l}91 \\
21 \\
17 \\
19 \\
15 \\
35\end{array}$ & $\begin{array}{r}101 \\
13 \\
8 \\
10 \\
22 \\
33\end{array}$ & $\begin{array}{l}2 \\
2 \\
0 \\
8 \\
1 \\
9\end{array}$ & $\begin{array}{l}3 \\
2 \\
0 \\
4 \\
2 \\
3\end{array}$ & $\begin{array}{l}4 \\
0 \\
1 \\
2 \\
1 \\
0\end{array}$ & & $\begin{array}{l}5 \\
0 \\
0 \\
2 \\
1 \\
1\end{array}$ \\
\hline Total & 198 & 187 & 22 & 14 & 8 & & 9 \\
\hline $\begin{array}{l}\text { Non-cardiac events } \\
\text { Nausea } \\
\text { Vomiting } \\
\text { Sweating } \\
\text { Urinary retention } \\
\text { Other }\end{array}$ & $\begin{array}{r}40 \\
30 \\
8 \\
3 \\
11\end{array}$ & $\begin{array}{r}37 \\
24 \\
5 \\
3 \\
11\end{array}$ & $\begin{array}{r}9 \\
6 \\
9 \\
0 \\
15\end{array}$ & $\begin{array}{l}6 \\
5 \\
4 \\
1 \\
5\end{array}$ & $\begin{array}{l}1 \\
0 \\
1 \\
0 \\
1\end{array}$ & & $\begin{array}{l}1 \\
0 \\
0 \\
0 \\
0\end{array}$ \\
\hline Total & 92 & 80 & 39 & 21 & 3 & & 1 \\
\hline
\end{tabular}

Table 5 Comparative characteristics of patients with and without primary ventricular fibrillation in group 1

\begin{tabular}{|c|c|c|c|}
\hline & Primary ventricular fibrillation & No primary ventricular fibrillation & \\
\hline $\begin{array}{l}\text { No. of patients } \\
\text { Acute myocardial infarction site }\end{array}$ & $\begin{array}{l}14 \\
11 \text { Inferior (79\%) } \\
2 \text { Anterior } \\
1 \text { Other }\end{array}$ & $\begin{array}{l}545 \\
235 \text { Inferior (43\%) } \\
255 \text { Anterior } \\
37 \text { Other } \\
18 \text { Unknown }\end{array}$ & $\mathrm{p}<0.05$ \\
\hline $\begin{array}{l}\text { Sex } \\
\text { Previous acute myocardial infarction } \\
\text { Age }(y) \\
\text { Delay time (h) } \\
\text { Initial heart rate (beats/min) } \\
\text { Initial systolic blood pressure (mmHg) } \\
\text { Initial diastolic blood pressure (mmHg) }\end{array}$ & $\begin{array}{l}12 M(86 \%) \\
2 \\
60.4 \\
2.6 \\
74.3 \\
149.6 \\
89.2\end{array}$ & $\begin{array}{l}445 M(82 \%) \\
88 \\
54.9 \\
3.4 \\
78 \cdot 5 \\
144.1 \\
91 \cdot 7\end{array}$ & $\begin{array}{l}\text { NS } \\
\text { NS } \\
p<0.05 \\
p<0.05 \\
\text { NS } \\
\text { NS } \\
\text { NS }\end{array}$ \\
\hline
\end{tabular}


Table 6 Patient characteristics of 14 primary ventricular fibrillation patients in group 1

\begin{tabular}{|c|c|c|}
\hline & Tocainide & Placebo \\
\hline $\begin{array}{l}\text { No. of patients } \\
\text { Men } \\
\text { Women } \\
\text { Mean age (y) } \\
\text { Mean delay time (h) } \\
\text { Previous acute myocardial infarction } \\
\text { Site of acute myocardial infarction-Inferior } \\
\text {-Anterior } \\
\text { Mean CK (IU/l) }\end{array}$ & $\begin{array}{l}9 \\
7 \\
2 \\
60 \\
2 \cdot 4 \\
2 \\
7 \\
1 \\
1 \\
2396 \text { (information from two patients only) }\end{array}$ & $\begin{array}{l}5 \\
5 \\
0 \\
61 \\
2 \cdot 8 \\
0 \\
4 \\
\frac{1}{2411} \text { (information from three } \\
\text { patients only) }\end{array}$ \\
\hline
\end{tabular}

1 failed to achieve a plasma level above the lower "therapeutic level" ( $3.5 \mathrm{mg} / \mathrm{l})$ while only two patients (2\%) were above the accepted upper "therapeutic level" $(9.0 \mathrm{mg} / \mathrm{l}) .12$ The corresponding figures for group 2 patients were $8 \%$ and $14 \%$. There was no significant correlation between plasma levels and ventricular fibrillation or unwanted effects.

\section{EXCLUDED PATIENTS}

At four centres the total population from which the study population was drawn was recorded. Of the 1253 patients considered for entry, only $131(11 \cdot 7 \%)$ were admitted to the trial. The main reasons for exclusion from the study were a delay time of more than six hours (34.3\%), previous antiarrhythmic therapy (mainly beta blockade) (17.3\%), age greater than 70 years $(11.0 \%)$, diagnosis not myocardial infarction $(9.2 \%)$, left ventricular failure $(8.7 \%)$, arrhythmias requiring specific treatment $(6.4 \%)$, and heart rate less than 50 beats/minute $(6.3 \%)$.

\section{Discussion}

An easily administered effective regimen to prevent primary ventricular fibrillation in acute myocardial infarction would have considerable clinical value. High dose intravenous lignocaine has been shown to reduce significantly the incidence of primary ventricular fibrillation but the regimen was cumbersome for out of hospital use. ${ }^{1}$ Most other studies of ventricular fibrillation prophylaxis have failed to reach a definite statistical conclusion as there were too few episodes of ventricular fibrillation. This double blind study of intravenous and oral tocainide has reached the definite conclusion that prophylactic administration of tocainide in the doses used does not reduce the incidence of primary ventricular fibrillation by as much as $50 \%$. Though this result might conceal a lesser effect on ventricular fibrillation, this would be of little practical benefit. This study and others ${ }^{710}$ have shown that tocainide is an effective antiarrhythmic agent particularly active against ventricular arrhythmias but, as shown by this study, extrapolation from drug effects against some ventricular arrhythmias to an effect oi the prophylaxis of ventricular fibrillation is not justified.

The structural and electrophysiological similarity of tocainide and lignocaine ${ }^{13}$ suggests that this drug might be a strong contender to reproduce the beneficial effects of lignocaine. The lack of a major effect of tocainide on ventricular fibrillation in this study ma have occurred for one of two reasons: either the dose used was inadequate or the drug is ineffective. If recent investigations higher doses of tocainide have been administered without important unwanted effects. ${ }^{14}$ In this study, patients who had sustained definite acute myocardial infarction had an acceptab incidence of unwanted effects but their plasme tocainide levels were lower than in those withouf infarction. If a higher tocainide dose had been use $\vec{G}$ even if an antifibrillatory effect had been detected, $\overline{\mathrm{H}}$ is possible that patients who had not sustained acue myocardial infarction would be at risk of excessive high plasma levels.

The design of a study to determine whether a druog is efficacious in ventricular fibrillation prophylaxis difficult. In acute myocardial infarction, ventricular. fibrillation is an early arrhythmic phenomenon and patients must be entered as soon as possible after pres sentation at hospital. In this study, recruitment was confined only to those patients admitted within sis hours of the onset of symptoms in an attempt restrict attention to those at particular risk of primari ventricular fibrillation. The incidence of primary verP tricular fibrillation, however, was surprisingly lod (six events in 281 placebo patients-a rate of $2.1 \%$ emphasising a further difficulty in the design and conduct of studies of this type. Moreover, the diag nosis of acute myocardial infarction based on clinic criteria at this early stage is likely to be correct in onf two-thirds of patients. Randomisation of patients to active or placebo therapy ideally should be doubere blind and result in two comparable patient group The group 1 tocainide and placebo patients in this study are very similar except in the distinct dispari in the site of infarction. There is no identifiable reason 
for this and we assume that it has occurred by chance.

There was a high incidence of death (two of 28) and of cardiac events (nine of 28) in group 3 patients (protocol violators and those with inadequate data). This phenomenon occurred both in active and placebo treated patients and, while our inclusion criteria were primarily designed to prevent inappropriate administration of tocainide, the figures indicate that patients who should be excluded from such investigations are themselves a high risk group. Similar findings have been noted in other studies. ${ }^{56}$

This study is one of very few which has arrived at a firm conclusion regarding the efficacy of a drug for ventricular fibrillation prophylaxis. Further investigations of drug prophylaxis of ventricular fibrillation are required and should employ a study design which permits a positive statistical statement of drug efficacy.

\section{References}

1 Lie KI, Wellens HJJ, Van Capelle FJ, Durrer D. Lidocaine in the prevention of primary ventricular fibrillation. $N$ Engl f Med 1974; 291: 1324-6.

2 Lie KI, Liem KL, Louridtz WL, Janse MJ, Willebrands AF, Durrer D. Efficacy of lignocaine in preventing ventricular fibrillation within 1 hour after a $300 \mathrm{mg}$ intramuscular injection. A double-blind, randomized study of 300 hospitalized patients with acute myocardial infarction. Am $\mathcal{F}$ Cardiol 1978; 42: 486-8.

3 Koch-Weser J, Klein SW, Foo-Canto LL, Kastor JA, DeSanctis RW. Antiarrhythmic prophylaxis with procainamide in acute myocardial infarction. $N$ Engl $f$ Med 1969; 281: 1253-60.

4 Jones DT, Kostuk WJ, Gunton RW. Prophylactic quinidine for the prevention of arrhythmias after acute myocardial infarction. Am f Cardiol 1974; 33: 655-60.

5 Campbell RWF, Achuff SC, Pottage A, Murray A, Prescott LF, Julian DG. Mexiletine in the prophylaxis of ventricular arrhythmias during acute myocardial infarction. F Cardiovasc Pharmacol 1979; 1: 43-52.

6 Campbell RWF, Bryson LG, Bailey BJ, Murray A, Julian DG. Prophylactic administration of tocainide in acute myocardial infarction. In: Pottage A, Ryden L, eds. Workshop on tocainide. Goteborg: AB Hässle, 1981: 201-4.

7 Rydén L, Arnman K, Conradson T-B, Hofvendahl S, Mortensen $\mathrm{O}$, Smedgård P. Prophylaxis of ventricular tachyarrhythmias with intravenous and oral tocainide in patients with and recovering from acute myocardial infarction. Am Heart f 1980; 100: 1006-12.

8 Prescott LF. Pharmacokinetic abnormalities in myocardial infarction. In: Sandøe E, Julian DG, Bell JW, eds. Management of ventricular tachycardia -role of mexiletine. Amsterdam: Excerpta Medica, 1978: 465-71.

9 Anderson JL, Mason JW, Winkle RA, et al. Clinical electrophysiologic effects of tocainide. Circulation 1978; 57: 685-91.

10 Rehnquist N. Comparison of tocainide with lidocaine in AMI. In: Pottage A, Ryden L, eds. Workshop on tocainide. Goteborg: AB Hässle, 1981: 187-9.

11 Graffner C, Conradson T-B, Hofvendahl S, Rydén L. Tocainide kinetics after intravenous and oral administration in healthy subjects and in patients with acute myocardial infarction. Clin Pharmacol Ther 1980; 27: 64-71.

12 Winkle RA, Meffin PJ, Fitzgerald JW, Harrison DC. Clinical efficacy and pharmacokinetics of a new orally effective antiarrhythmic agent, tocainide. Circulation 1976; 54: 884-9.

13 Moore EN, Spear JF, Horowitz LN, Feldman HS, Moller RA. Electrophysiologic properties of a new antiarrhythmic drug-tocainide. Am $\mathcal{f}$ Cardiol 1978; 41: 7039.

14 Young MD, Hadidian Z, Horn HR, Johnson JL, Vassallo HG. Treatment of arrhythmias with oral tocainide. Am Heart F 1980; 100: 1041-5.

Requests for reprints to Dr R W F Campbell, University Department of Cardiology, Freeman Hospital, Newcastle upon Tyne NE7 7DN.

\section{Erratum}

The authors regret the following error in their paper in the May issue on "Two dimensional echocardiography and the tricuspid valve. Leaflet definition and prolapse". In the Summary, page 495, line 3, "tricuspid valve prolapse" should read "tricuspid valve regurgitation". 